

\section{DISCLAIMER}

This report was prepared as an account of work sponsored by an agency of the United States Government. Neither the United States Government nor any agency Thereof, nor any of their employees, makes any warranty, express or implied, or assumes any legal liability or responsibility for the accuracy, completeness, or usefulness of any information, apparatus, product, or process disclosed, or represents that its use would not infringe privately owned rights. Reference herein to any specific commercial product, process, or service by trade name, trademark, manufacturer, or otherwise does not necessarily constitute or imply its endorsement, recommendation, or favoring by the United States Government or any agency thereof. The views and opinions of authors expressed herein do not necessarily state or reflect those of the United States Government or any agency thereof. 


\section{DISCLAIMER}

Portions of this document may be illegible in electronic image products. Images are produced from the best available original document. 


\section{Printed in the United States of America. Available from National Technical Information Service \\ U.S. Department of Commerce}

5285 Port Royal Road, Springfield, Virginia 22161

NTIS price codes-Printed Copy: A02; Microfiche A01

This report was prepared as an account of work sponsored by an agency of the United States Government. Neither the United States Government nor any agency thereof, nor any of their employees, makes any warranty, express or implied, or assumes any legal liability or responsibility for the accuracy, completeness, or usefulness of any information, apparatus, product, or process disclosed, or represents that its use would not infringe privately owned rights. Reference herein to any specific commercial product, process, or service by trade name, trademark, manufacturer, or otherwise, does not necessarily constitute or imply its endorsement, recommendation, or favoring by the United States Government or any agency thereof. The views and opinions of authors expressed herein do not necessarily state or reflect those of the United States Government or any agency thereof. 
ORNL/TM-7400

Contract No. W-7405-eng-26

\author{
Energy Division
}

THE COMPOSITION OF GASES VENTED FROM A CONDENSER

R. N. LYON

Date Published: August 1980

Prepared by

OAK RIDGE NATIONAL LABORATORY

Oak Ridge, Tennessee 37830

Operated by

UNION CARBIDE CORPORATION

for the

DEPARTMENT OF ENERGY

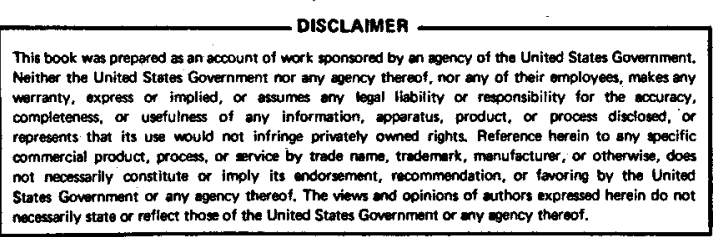




$$
1
$$

$\bullet$

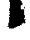

$\bullet$

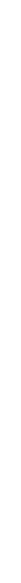

2

$\because$

$+$ 


\section{CONTENTS}

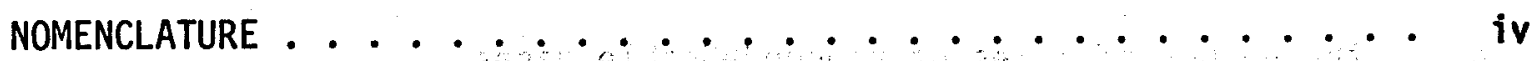
ABSTRACT . . . . . . . . . . . . . . . . . . 1

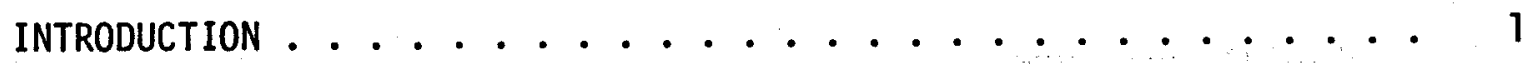

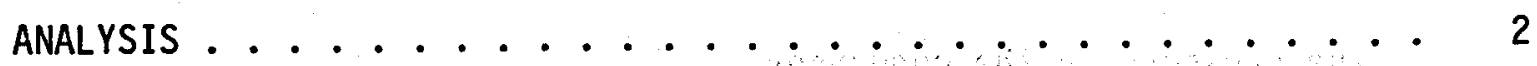

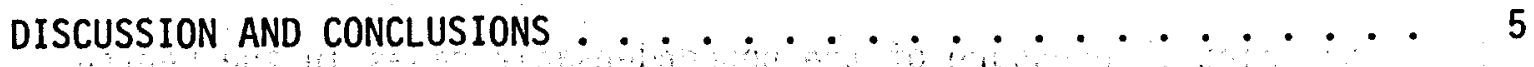

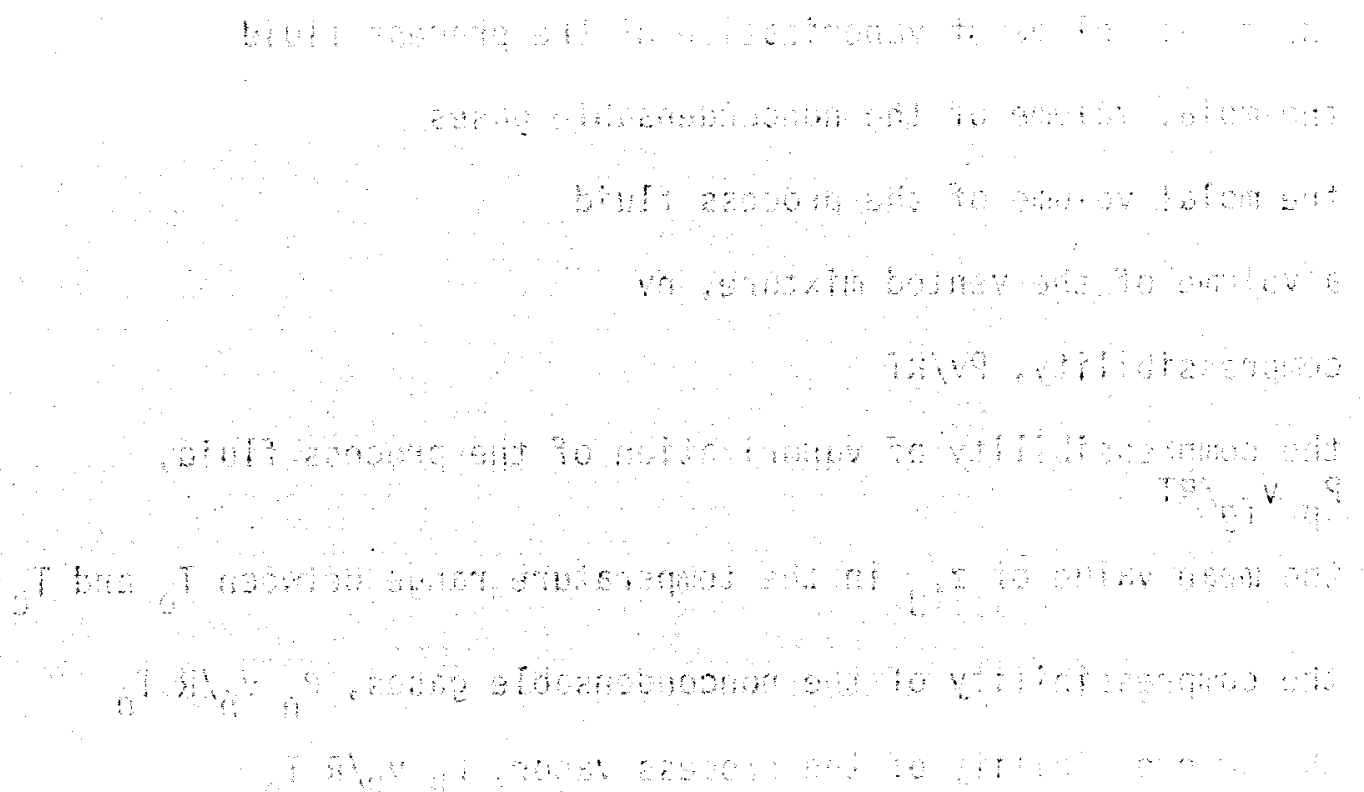


NOMENCLATURE

$h_{f g}$ the molal heat of vaporization of the process fluid

$\overline{h_{f g}}$ the mean value of $h_{f g}$ in the temperature range between $T_{0}$ and $T_{c}$

$\mathrm{n}$ the number of moles of a constituent of the vented mixture

$n_{n} \quad$ the number of moles of noncondensable gases

$n_{p}$ the number of moles of process vapor

P absolute pressure

$p_{c}$ the pressure in the condenser

$P_{n}$ the partial pressure of the noncondensable gases in the vented mixture

$P_{p} \quad$ the partial pressure of the process vapor in the vented mixture

$R$ the gas constant

T absolute temperature

$T_{c}$ the saturation temperature of the process fluid at $P_{c}$

$T_{0}$ the temperature at which the vented mixture leaves the condenser

$\checkmark$ molal volume

$v_{f g}$ the molal volume of vaporization of the process fluid

$v_{n} \quad$ the molal volume of the noncondensable gases

$v_{p} \quad$ the molal volume of the process fluid

V a volume of the vented mixture, $\mathrm{nv}$

z compressibility, PV/RT

$\mathrm{z}_{\mathrm{fg}}$ the compressibility of vaporization of the process fluid, $P_{p} v_{f g} / R T$

$\overline{z_{f g}}$ the mean value of $z_{f g}$ in the temperature range between $T_{0}$ and $T_{C}$

$z_{n} \quad$ the compressibility of the noncondensable gases, $P_{n} v_{n} / R T_{0}$

$z_{p}$ the compressibility of the process vapor, $P_{p} v_{p} / R T_{0}$ 


\title{
THE COMPOSITION OF GASES VENTED FROM A CONDENSER
}

\author{
R. N. Lyon
}

\section{ABSRACT}

Designers of systems that involve condensers of ten need to predict the amount of process vapor that accompanies the noncondensable gases that are vented from the condensers.

The following approximation appears to provide, in many cases, reasonably accurate values for the mole ratio of process vapor to noncondensable gases in the vented mixture:

$$
\frac{n_{p}}{n_{n}} \approx \frac{R T_{c} T_{0}}{h_{f g}\left(T_{c}-T_{0}\right)}-\frac{1}{2}
$$

The approximation is particularly applicable to flash and directcontact power systems for geothermal brines and ocean thermal energy conversion (OTEC). cases.

More rigorous relationships are available for exceptional

\section{INTRODUCTION}

Well designed condensers flow the process vapor from the condenser inlet across the condensing region to a vent region where noncondensable gases can be removed continuously, or accumulated for periodic removal. When the process fluid is used in a closed Rankine cycle entirely above atmospheric pressure, the principal source of noncondensable gas will be that dissolved in make-up fluid, and venting is usually not a serious problem, At the opposite extreme is a subatmospheric condenser for vapor being condensed by direct contact with a stream of water, or other cool fluid, that is saturated with gas at atmospheric pressure and where

\footnotetext{
${ }^{*}$ Consultant, Energy Division.
} 
the vapor originates either from or in direct contact with warm fluid that is also saturated with noncondensable gases.

The latter situation occurs, for example, in flash and directcontact systems for geothermal power plants and for ocean thermal energy conversion (OTEC).

The gaseous mixture that is withdrawn from condensers will be saturated with the process-fluid vapor at the temperature of withdrawal, and this can pose several problems:

1. If the vapor is flammable, it must be recovered or flared to avoid the danger of fire or explosion.

2. The process fluid may be sufficiently valuable to require recovery from vented mixture.

3. If the condenser operates below atmospheric pressure, a vent compressor will be required. The power required by the first stage or two of a mechanical compressor will usually be dominated by the power required for adiabatic compression of the process vapor in the mixture that is being compressed in that stage, and the bulk of the heat removed in the first few interstage coolers will be the latent heat of the condensing process vapor. Water-jet and barometric-leg compressors tend, in principle, to approach isothermal compression, but the size of the compressor is determined by the volume flow rate of the incoming mixture from the condenser.

For these and perhaps other reasons, designers need to estimate the amount of process vapor in the effluent mixture as a function of $P_{c}$, the condenser pressure, and $T_{0}$, the temperature at which the mixture leaves the condenser.

\section{ANALYSIS}

In those cases where the constituents of the vented mixture all behave as ideal gases, we find, as described below, that

$$
\frac{n_{p}}{n_{n}} \approx \frac{R T_{c} T_{o}}{\overline{n_{f g}}\left(T_{c}-T_{0}\right)}-\frac{1}{2} \text {, }
$$


where $n_{p} / n_{n}$ is the mole ratio of process vapor to noncondensable gas in the mixture, $R$ is the gas constant, $T_{c}$ is the saturation temperature of the pure process vapor at $P_{c}$, the pressure of the condenser, and $\overline{h_{f g}}$ is a mean value of the molal heat of vaporization of the process fluid in the temperature range between $T_{0}$ and $T_{c}$ :

Development of Approximation (1) discloses the assumptions that it includes, and indicates more rigorous equations or approximations for nonideal gases and vapors.

We start by defining the "compressibility" of any gas or vapor as

$$
z \equiv \frac{P V}{R T},
$$

where, of course, $P$ and $T$ are the absolute pressure and absolute temperature of the gas, and $v$ is its molal volume. The compressibility will be unity for an ideal gas, and its value for saturated vapors does not change as rapidly with temperature as does the specific volume.

We next make the assumption that each constitutent gas fills the volume, $v=n v$, that is occupied by the mixture and that it has no interaction with any of the other constitutent gases, except that the sum of the individual partial pressures of the constituent gases is $P_{C}$, the total pressure in the condenser.

We also assume that the noncondensable gases are insufficientiy: soluble in the liquid process fluid to effect a serious change in the saturation temperature of the liquid. These are both reasonable assumptions, for example, if oxygen and nitrogen are the noncondensable gases, and if water, Freon, or a light hydrocarbon is the process fluid.

It follows from those assumptions that

$$
\frac{n_{p}}{n_{n}}=\frac{z_{n} P_{p}}{z_{p} P_{n}}=\frac{z_{n} P_{p}}{z_{p}\left(P_{c}-P_{p}\right)}
$$

where, again, the subscripts $p$ and $n$ refer to the process fluid and noncondensable gases. 
We now draw on the Clapeyron equation:

$$
\left(\frac{\partial P}{\partial T}\right)_{\text {saturation }}=\frac{h_{f g}}{T v_{f g}},
$$

where $v_{f g}$ is the increase in molal volume of the process fluid when it vaporizes.

If we define a compressibility of vaporization as

$$
z_{f g} \equiv \frac{P v_{f g}}{R T},
$$

we obtain a modified Clausius-Clapeyron equation:

$$
P_{p}=P_{c} \exp \left[\frac{\overline{h_{f g}}\left(T_{0}-T_{c}\right)}{\frac{z_{f g}}{z_{0}} T_{0} T_{c}}\right]
$$

and

$$
\frac{n_{p}}{n_{n}}=\frac{z_{n}}{z_{p}} \frac{1}{\exp \left[\frac{\overline{h_{f g}}\left(T_{c}-T_{0}\right)}{\overline{z_{f g}} R T_{c} T_{0}}\right]-1}
$$

Next, we note that

$$
\frac{1}{e^{x}-1} \approx \frac{1}{x}-\frac{1}{2}
$$

within about $10 \%$ or less, when $x<0.9$ :

\begin{tabular}{lcccccccc}
\multicolumn{1}{c}{$x$} & 0 & 0.1 & 0.3 & 0.5 & 0.7 & 0.8 & 0.9 & 1.0 \\
$1 /\left(\mathrm{e}^{\mathrm{x}}-1\right)$ & $\infty$ & 9.51 & 2.86 & 1.54 & 0.99 & $0.8 ?$ & 0.69 & 0.58 \\
$1 / \mathrm{x}-1 / 2$ & $\infty$ & 9.50 & 2.83 & 1.50 & 0.93 & 0.75 & 0.61 & 0.50 \\
$\%$ error & - & -0.09 & -0.9 & -3 & -6 & -8 & -11 & -14
\end{tabular}

Thus, we find that 


$$
\frac{n_{p}}{n_{n}} * \frac{z_{n}}{z_{p}}\left[\frac{z_{f g} R T_{c} T_{0}}{{ }_{h_{f g}}\left(T_{c}-T_{0}\right)}-\frac{1}{2}\right]
$$

and when the compressibilities all approach unity,

$$
\frac{n_{p}}{n_{n}} \approx \frac{R T_{c} T_{0}}{n_{f g}\left(T_{c}-T_{0}\right)}-\frac{1}{2}
$$

\section{DISCUSSION AND CONCLUSIONS}

At $300^{\circ} \mathrm{K}\left(80^{\circ} \mathrm{F}\right), \mathrm{h}_{\mathrm{fg}} / \mathrm{RT}=18$ for water and $=8$ for isobutane. Thus, with water as the process fluid, we need to keep $\left(T_{C}-T_{0}\right) / T$ to less than about 0.05 if we use Approximation (1).

In the case of isobutane, the error can be held to $10 \%$ or less if $\left(T_{c}-T_{0}\right) / T$ is 0.1 or less; but we need to check to see whether we should use Approximation (9), since for isobutane at that temperature, $z_{p}=0.90$ and $z_{f g}=0.88$. At $278 \mathrm{~K}\left(40^{\circ} \mathrm{F}\right), z_{p}$ for isobutane is 0.94 and $z_{f g}$ is 0.93 . In OTEC systems the value of $\left(T_{c}-T_{0}\right) / T$ will usually be less than 0.02 . This means that if water is the process fluid, and if the noncondensables are nitrogen, oxygen, and any other gases that behave like ideal gases, the mole ratio of the vented mixture will be greater than 2.3 moles of water to one mole of noncondensable gas. If, as is more likely, $\left(T_{c}-T_{0}\right) / T$ is 0.01 , then the effluent mixture will contain 5.1 moles of water vapor per mole of noncondensable:

\begin{tabular}{|c|c|c|c|c|c|c|c|}
\hline \multirow{3}{*}{ Temperature } & \multirow{3}{*}{$\frac{h_{f g}}{R T}$} & \multirow{3}{*}{$2 p$} & \multirow{3}{*}{$z_{f g}$} & \multicolumn{4}{|c|}{ Moles, Process Fluid/Mole, Noncondensables } \\
\hline & & & & \multicolumn{2}{|c|}{$\left(T_{c}-T_{0}\right) / T=0.02$} & \multicolumn{2}{|c|}{$\left(T_{c}-T_{0}\right) / T=0.01$} \\
\hline & & & & Appr. (9) & Appr. (1) & Appr. (9) & Appr. (1) \\
\hline \multicolumn{8}{|l|}{ Water } \\
\hline $300 \mathrm{~K}\left(80^{\circ} \mathrm{F}\right)$ & 18 & 1 & 1 & 2.3 & 2.3 & 5.1 & 5.1 \\
\hline $278 \mathrm{~K}\left(40^{\circ} \mathrm{F}\right)$ & 19 & 1 & 1 & 2.1 & 2.1 & 4.8 & 4.8 \\
\hline \multicolumn{8}{|l|}{ Isobutane } \\
\hline $300 \mathrm{~K}\left(80^{\circ} \mathrm{F}\right)$ & 8 & 0.90 & 0.88 & 5.6 & 5.8 & 11.7 & 12.0 \\
\hline $278 \mathrm{~K}\left(40^{\circ} \mathrm{F}\right)$ & 9 & 0.94 & 0.93 & 5.0 & 5.1 & 10.5 & 10.6 \\
\hline
\end{tabular}


In the above calculations, we have not differentiated between $T_{C}$, $T_{0}$, and an intermediate temperature at which we calculate $\overline{h_{f g}}$ and $\frac{c^{\prime}}{z_{f g}}$. It appears from the results, however, that only a few percent error is involved in that lack of rigor.

The compressibilities of saturated vapors are always unity or less. Thus, the vaporization compressibility and the simple compressibility of the process vapor will always tend to cancel each other in Eq. (7) and Approximation (9). That fact is illustrated by the close agreement between the results for isobutane using Approximations (9) and (1).

On the other hand, as seen in Eq. (7) and Approximation (9), the mole ratio in the vented mixture will be exactly proportional to the compressibility of the noncondensable gases. 


\section{INTERNAL DISTRIBUTION}

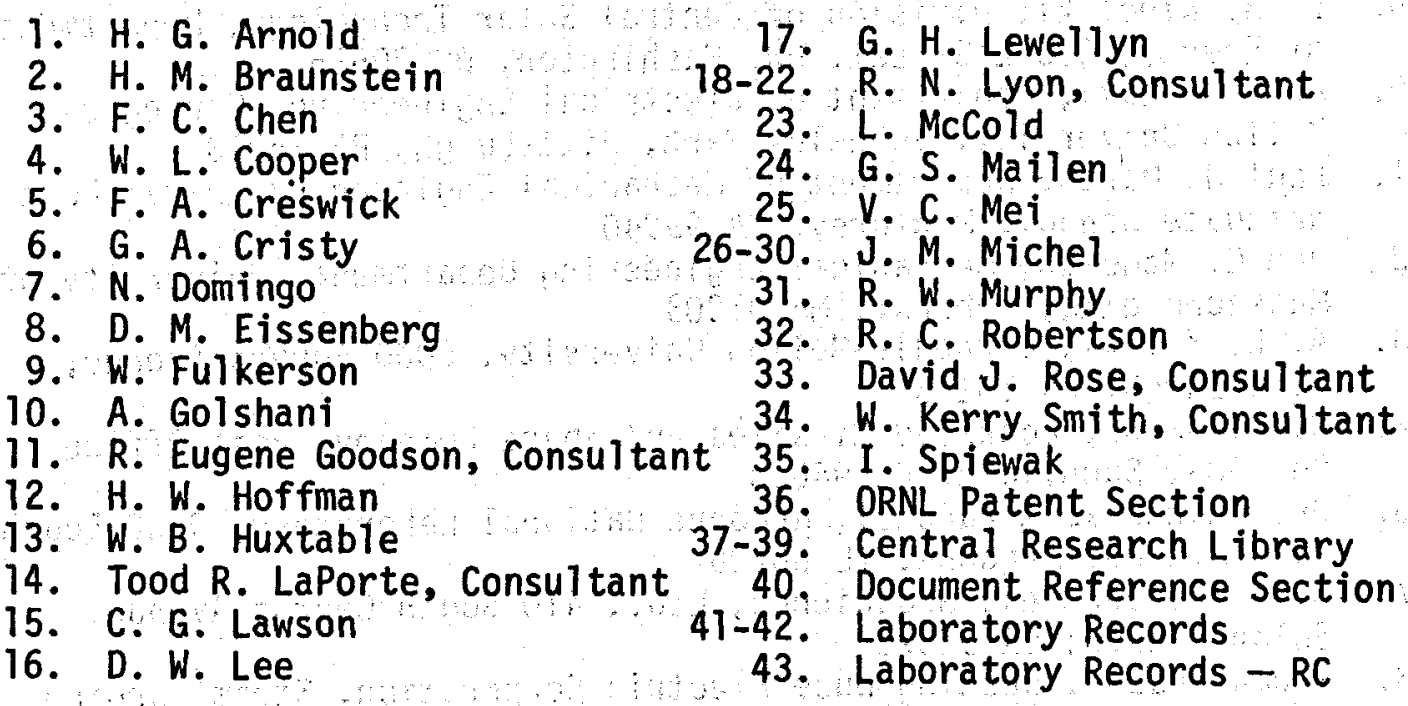

\section{EXTERNAL DISTRIBUTION}

44. Assistant Manager for Office of Energy Research and Development, DOE/ORO

45. James H. Anderson, Jr., Sea Solar Power, Inc., 2422 S. Queen Street, York, $P A 17402$

46. William H. Avery, Applied Physics Laboratory, Johns Hopkins University, Johns Hopkins Road, Laurel, MD 20810

47. Eugene Barsness, Westinghouse Electric Corporation, Steam Turbine Division, Lester Branch Box 9175 , Philadelphia, PA 19113

48. Kenneth J. Bell, School of Chemical Engineering, Oklahoma state University, Stillwater, OK 74074

49. A. F. Charwat, University of California, Department of Mechanics and Structures, 5731 Boel ter Hall, Los Angeles, CA 90024

50. Dr. D. Chisholm, National Engineering Laboratory, Glasgow, Scotland

51. Robert S. Cohen, Division of Central Solar Technology, Department of Energy, 600 E Street, NW, Washington, DC 20585

52. Roland L. Coit, Electric Power Research Institute, Post Office Box 10412, Palo Al to, CA 94303

53. Robert H. Douglass, TRW, Inc., Systems and Energy Group, I Space Park, Redondo Beach, CA 90278

54. Gordon L. Dugger, Applied Physics Laboratory, Johns Hopkins University, Johns Hopkins Road, Laurel, MD 20810

55. Michael B. Foley, System Planning Department, Florida Power Corporation, 320134 th Street, South, St. Petersburg, FL:33733

56. Sigmond Gronich, Division of Central Solar Technology, Department of Energy, $600 \mathrm{E}$ Street, NW, Washington, DC 20585

57. R. Philip Hammond, R\&D Associates, 4640 Admiralty Way, Post Office Box 9693, Marina del Rey, CA 90291 
58. M. I. Kay, Center for Energy and Environmental Research, University of Puerto Rico, College Station, Mayaguez, Puerto Rico 00708

59. E. H. Kinelski, Division of Central Solar Technology, Department of Energy, 600 E Street, NW, Washington, DC 20585

60. Abrahim Lavi, Department of Electrical Engineering, CarnegieMellon University, Schenley Park, Pittsburgh, PA 15213

61. Paul J. Marto, Department of Mechanical Engineering, Naval Postgraduate School, Monterey, CA 93940

62. Jon G. McGowan, Mechanical Engineering Department, University of Massachusetts, Amherst, MA 01003

63. A. E. Molini, Carnegie-Mellon University, 5000 Forbes Avenue, Pittsburgh, PA 15213

64. W. L. Owens, Lockheed Missiles and Space Company, Post Office Box 504, Sunnyvale, CA 94088

65. Dr. Chandrakant Panchel, Argonne National Laboratory, 9700 South Cass Avenue, Argonne, IL 60439

67. H. F. Poppendiek, Geoscience, Ltd., 410 South Cedros Avenue, Solano Beach, CA 92075

68. Thomas Rabas, Westinghouse Electric Corporation, Steam Turbine Division, Lester Branch Box 9175, Philadelphia, PA 19113

69. Kenneth F. Read, 448 Ferry Point Road, Annapol is, MD 21403

70. Stuart L. Ridgway, R\&D Associates, 4640 Admiralty Way, Post Office Box 9695, Marina del Rey, CA 90291

71. Dr. J. W. Rose, Queen Mary College, University of London, London, England

72. Robert R. Rothfus, Carnegie-Mellon Universłty, 5000 Forbes Avenue, Pittsburgh, PA 15213

73. Cullen M. Sabin, Geoscience, Ltd., 410 South Cedros Avenue, Solano Beach, CA 92075

74. Norman Sather, Argonne National Laboratory, 9700 South Cass Avenue, Argonne , IL 60439

75. Lloyd A. Spielman, Department of Civil/Chemical Engineering, University of Delaware, Newark, DE 19711

76. Benjamin Shelpuk, Solar Energy Research Institute, 1536 Cole Boulevard, Golden, CO 80401

77. Anthony Thomas, Argonne National Laboratory, 9700 South Cass Avenue, Argonne, IL 60439

78. Graham B. Wallis, Thayer School of Engineering, Dartmouth College, Hanover, NH 03755

79. A. D. Watt, Engineering of Physics Department, Colorado School of Mines, Route 1 Box 183-1/2, Cedaredge, CO 81413

80. Laskar Wechsler, Hydraonautics, Inc., Pinde11 School Road, Laurel, MD 20810

81. Alvin Weinberg, Institute for Energy Analysis, Post Office Box 117, Oak Ridge, TN 37830

82. Clarence Zener, Physics Department, Carnegie-Mellon University, 5000 Forbes Avenue, Pittsburgh, PA 15213

83-109. Technical Information Center, Post Office Box 62, Oak Ridge, TN 37830 